\title{
Computed tomography findings in 15 cases of Creutzfeldt-Jakob disease with histological verification
}

\author{
SERGIO GÁLVEZ, ${ }^{*}$ LUIS CARTIER† \\ From the Department of Neurology, Instituto de Neurocirugía e Investigaciones Cerebrales* and the \\ Department of Neurology and Neuropathology, Hospital del Salvador, $\uparrow$ Santiago de Chile, Chile
}

SUMMARY Computed tomography (CT) was normal in twelve of fifteen patients with definite Creutzfeldt-Jakob disease. In two patients CT showed mild sulcal widening, while marked ventricular enlargement and moderate cortical atrophy were seen in a patient who had both Creutzfeldt-Jakob disease and normal pressure hydrocephalus. No correspondence was observed between CT findings, severity of the clinical picture and postmorten gross brain examination. According to these results, a normal CT in a demented patient should suggest Creutzfeldt-Jakob disease. Conversely, CT is of value for the diagnosis of other potentially reversible illnesses clinically resembling Creutzfeldt-Jakob disease.

In recent years computed tomography (CT) has been extensively used to evaluate patients with senile and presenile dementia mainly of the Alzheimer type. ${ }^{1-3}$ Since few reports deal with CT examination in Creutzfeldt-Jakob disease, ${ }^{45}$ a comparatively rare and rapidly evolving transmissible dementia of adult life, we present the CT findings in a series of fifteen patients with histologically verified Creutzfeldt-Jakob disease. The CT findings are compared with the clinical features and postmortem gross examination of the brains.

\section{Materials and methods}

We studied 15 consecutive patients with Creutzfeldt-Jakob disease who were seen between 1979 and 1983 (table). All were personal cases of the authors and some of them have been published elsewhere..$^{6-8}$ Five were males and ten were females, with a mean age at death of 54.6 years (range 39 to 66 years). The mean total duration of the disease was 6.7 months (range 2.5 to 12 months). The histological diagnosis was made by necropsy (seven patients), brain biopsy and autopsy (five patients) and

Address for reprint requests: Dr Gálvez. Instituto de Neurocirugía e Investigaciones Cerebrales, P.O. Box 3717, Santiago de Chile, Chile.

Received 9 February 1984 and in revised form 14 April 1984. Accepted 29 April 1984 brain biopsy alone (three patients). The disease was subsequently transmitted from patients 1,2 and 3 into laboratory animals. In patient 3 isotopic cisternography and ventriculography demonstrated a normal pressure hydrocephalus associated with histologically proved Creutzfeldt-Jakob disease. ${ }^{8}$

In patients $4,5,7,9,10,11,13$ and $15 \mathrm{CT}$ was performed early in the course of the disease, between 1 and 2 months after the clinical onset. In patients $1,2,3,6,8,12$ and 14 the CT scans were made later, between 4 and 8 months after the onset of symptoms and between 1 and 3 months before death.

\section{Results}

In twelve of the fifteen patients CT provided no evidence of brain atrophy, irrespectively of the time elapsed between the clinical onset and CT examination (see table). Thus, eight patients had a normal CT scan in an early stage of the disease, either when the clinical picture consisted only of psychological symptoms (patients $4,5,11,13$ and 15 ), or after the acute or subacute presentation of neurological signs preceding the psychological disturbances (patients 7, 9 and 10). On the other hand, in four patients with a CT scan performed later, between 4 and 8 months after the apparent clinical onset, and between 1 and 3 months before death (patients 1, 2, 12 and 14), no abnormal neuroradiological findings were observed. In addition, patients 1 and 12 and 1244 
Table CT and necropsy findings in 15 patients with defunite Creutzfeldt-Jakob disease

\begin{tabular}{|c|c|c|c|c|c|c|}
\hline & Case & $\begin{array}{l}\text { Sex } \\
\text { Age }\end{array}$ & $\begin{array}{l}\text { Disease } \\
\text { duration } \\
\text { (months) }\end{array}$ & $\begin{array}{l}\text { Interval between } \\
\text { onset/CT } \\
\text { (months) }\end{array}$ & $C T$ findings & $\begin{array}{l}\text { Postmortem gross } \\
\text { brain examination }\end{array}$ \\
\hline 1 & AAC & F 49 & 7 & 5 & normal & normal \\
\hline 2 & CVP & F 42 & 11 & 8 & normal & cortical atrophy + \\
\hline 3 & JRC & M 60 & 8 & 5 & $\begin{array}{l}\text { cortical atrophy }+ \\
\quad \text { ventricular dilatation }+++\end{array}$ & $\begin{array}{l}\text { cortical atrophy }+ \\
\text { ventricular dilatation }+++\end{array}$ \\
\hline 4 & LVV & M 45 & 12 & 2 & normal & $\begin{array}{l}\text { cortical atrophy }++ \\
\text { ventricular dilatation }+\end{array}$ \\
\hline 5 & LGG & F 63 & 9 & 2 & normal & normal \\
\hline 6 & MEP & M 59 & 8 & 5 & cortical atrophy + & cortical atrophy + \\
\hline 7 & EVV & F 53 & 3 & 1 & normal & cortical atrophy + \\
\hline 8 & EGM & F 66 & 7 & 6 & cortical atrophy + & cortical atrophy + \\
\hline 9 & LAP & F 39 & $5 \cdot 5$ & 1 & normal & $\begin{array}{l}\text { cortical atrophy }++ \\
\text { ventricular dilatation }++\end{array}$ \\
\hline 10 & $\mathrm{CSH}$ & F 62 & 4 & 2 & normal & $\begin{array}{l}\text { cortical atrophy }+ \\
\text { ventricular dilatation }+\end{array}$ \\
\hline 11 & MLV & F 57 & 3 & 1 & normal & normal \\
\hline 12 & MUA & F 60 & 7 & 4 & normal & only brain biopsy \\
\hline 13 & MMR & M 56 & 5 & 1 & normal & only brain biopsy \\
\hline 14 & BMM & M 55 & 9 & 6 & normal & only brain biopsy \\
\hline 15 & ARO & M 53 & $2 \cdot 5$ & 1 & normal & normal \\
\hline
\end{tabular}

Mean age at death $54 \cdot 6$ years.

Mean illness duration 6.7 months.

three with no detectable abnormalities on CT performed a few weeks after the onset of symptoms (patients 4, 10 and 15) showed typical periodic activity in the EEGs obtained at the time of normal CT.

Nine of the twelve patients with normal CT had necropsy, while in three the neuropathologic study was restricted to brain biopsy material. No gross atrophy of the brain was observed in patients 1,5 , 11 and 15 and only mild sulcal widening existed in patients 2 and 7 . Patient 4, with the longest disease duration (12 months) showed moderate bifrontal cortical atrophy and enlarged ventricles, as did patients 9 and 10 with normal early CT scans and a rather short disease duration of 5.5 and 4 months, respectively. The brain of patients 9 and 10 weighed less than $1000 \mathrm{~g}$ and accordingly the microscopical examination revealed the most marked and widespread histopathological features of CreutzfeldtJakob disease in this group of patients.

In patients 6 and $8 \mathrm{CT}$ had shown mild widening of cortical sulci 5 to 6 months after the clinical onset; however, the necropsy of both patients showed questionable external gross atrophy of the brain and normal sized ventricles. In patients 2,6 and 9 with the clinical features of the ataxic variety of Creutzfeldt-Jakob disease, cerebellar atrophy was not seen in either CT or necropsy examinations. As already stated, in patient 3 the marked enlargement of both lateral and third ventricles and moderate sulcal widening demonstrated by CT did not correspond to a passive hydrocephalus, but to a normal pressure hydrocephalus in unusual combination with definite Creutzfeldt-Jakob disease diagnosed by brain biopsy, necropsy and experimental transmission.

\section{Discussion}

For many years necropsy examination, pneumoencephalography and isotopic cisternography have shown that brain atropy is often associated with dementia. ${ }^{9-11}$ Although the advent of CT has provided a better correlation between both phenomena, age-related brain atrophy may be observed in normal old people without intellectual impairment. Conversely, dementia may occur in the absence of brain atrophy demonstrable by CT. Some authors have postulated that cases of dementia without atrophy should correspond to potentially treatable and reversible illnesses. ${ }^{12}$ Our results, however, do not support this view, since CT was normal in $80 \%$ of our patients with CreutzfeldtJakob disease, a uniformly fatal dementing disease. In addition, in three of eight Creutzfeldt-Jakob disease patients reviewed by Zieger et $\mathrm{al}^{5} \mathrm{CT}$ did not reveal abnormalities during the fully developed disease, and one of them dying after a total course of 8 months did not present postmortem gross atrophy of the brain. Since approximately half of our patients were submitted to CT examination in an advanced stage of the disease, an outstanding feature of the series reported here is the lack of correlation between CT and the patients clinical condition on one hand and between antemortem normal CT and postmortem gross brain atrophy on the other.

One possible explanation for the low yield of abnormal CT findings in Creutzfeldt-Jakob disease 
could be the well-known short mean duration of the disease (6.7 months in the present series). CT performed too early after the clinical onset could be an additional reason. Thus, CT scans obtained within the first few weeks after onset in about half of our patients would account for the normal findings, while the necropsy-proved gross brain atrophy and the intense and widespread histopathological lesions observed 2 to 4.5 months after the normal scans in our patients 9 and 10 would suggest an hypothetical highly aggressive Creutzfeldt-Jakob disease virus strain. Furthermore, the better yield of antemortem CT abnormalities reported in Zieger's review ${ }^{5}$ may be attributable to serially performed scans in four of the eight patients.

Despite these considerations, CT should be the initial diagnostic procedure in patients with symptoms suggestive of Creutzfeldt-Jakob disease. The accurate early diagnosis of Creutzfeldt-Jakob disease is often difficult because of the frequent presentation of atypical cases and also because other treatable diseases may closely mimic its clinical onset. ${ }^{13}$ Consequently, patients with undiagnosed low pressure hydrocephalus, chronic subdural haematoma or other potentially reversible intracranial processes mimicking the early clinical features of CreutzfeldtJakob disease will benefit from appropriate treatment. On the contrary, a normal CT in a senile or presenile patient developing subacute dementia should suggest Creutzfeldt-Jakob disease. Finally, the non-invasive nature of $\mathrm{CT}$ is of importance in avoiding the risk of the iatrogenic person-to-person transmission of Creutzfeldt-Jakob disease.

\section{References}

' Fox JH, Huckman MS, Topel JL. Use of computerized tomography in senile dementia. J Neurol Neurosurg Psychiatry 1975;38:949-53.

${ }^{2}$ Merskey H, Ball MJ, Blume WT, et al. Relationships between psychological measurements and cerebral organic changes in Alzheimer's disease. Can J Neurol Sci 1980; 7:45-9.

${ }^{3}$ Soininen H, Puranen M, Riekkinen P. Computed tomography findings in senile dementia and normal aging. J Neurol Neurosurg Psychiatry 1982;45:50-4.

${ }^{4}$ Rao CVG, Brennan TG, Garcia JH. Computed tomography in the diagnosis of Creutzfeldt-Jakob disease. J Comput Assist Tomogr 1977;1:211-5.

${ }^{5}$ Zieger A, Vonofakos D, Vitzhum HG. CreutzfeldtJakobsche Krankheit: Das Computertomogramm in Korrelation zu klinischen, elektroenzephalographischen und neuropathologischen Befunden. Der Nervenarzt 1981;52:685-91.

${ }^{6}$ Gálvez S, Cartier L. A new familial clustering of Creutzfeldt-Jakob disease in Chile. Neurocirugia (Chile) 1979;37:58-65.

${ }^{7}$ Gálvez S, Cartier L. Creutzfeldt-Jakob disease. Anatomoclinical report of two cases with acute stroke-like onset. Rev Chil Neuro-Psiquiatr 1983; 21:223-7.

${ }^{8}$ Gálvez S, Ferrer S, Cartier L, Palma A. Subacute spongiform encephalopathy (Creutzfeldt-Jakob disease) associated with normal pressure hydrocephalus. Anatomoclinical report of one case. Acta Neurochir 1980;51:227-32.

${ }^{9}$ Tomlinson BE, Blessed G, Roth M. Observations on the brains of demented old people. J Neurol Sci 1970;11:205-42.

${ }^{10}$ Nielsen $R$, Petersen $O$, Thygesen $P$, Willanger $R$. Encephalographic cortical atrophy, relationships to ventricular atrophy and intellectual impairment. Acta Radiol Diagn 1966;4:437-48.

"Di Chiro G, Reames PM, Matthews WB Jr. RISAventriculography and RISA-cisternography. Neurology (Minneap) 1964;14:185-91.

12 Huckmans MS, Fox JH, Topel JL. The validity of criteria for the evaluation of cerebral atrophy by computed tomography. Neuroradiology 1975; 116:85-92.

${ }^{13}$ Bernoulli C, Masters CL, Gajdusek DC, Gibbs CJ Jr, Harris JO. Early clinical features of Creutzfeldt-Jakob disease (subacute spongiform encephalopathy. In: Prusiner SB, Hadlow WJ, eds. Slow Transmissible Diseases of the Nervous System, vol 1. New York: Academic Press, 1979:229-51. 